This item was submitted to Loughborough's Institutional Repository (https://dspace.lboro.ac.uk/) by the author and is made available under the following Creative Commons Licence conditions.

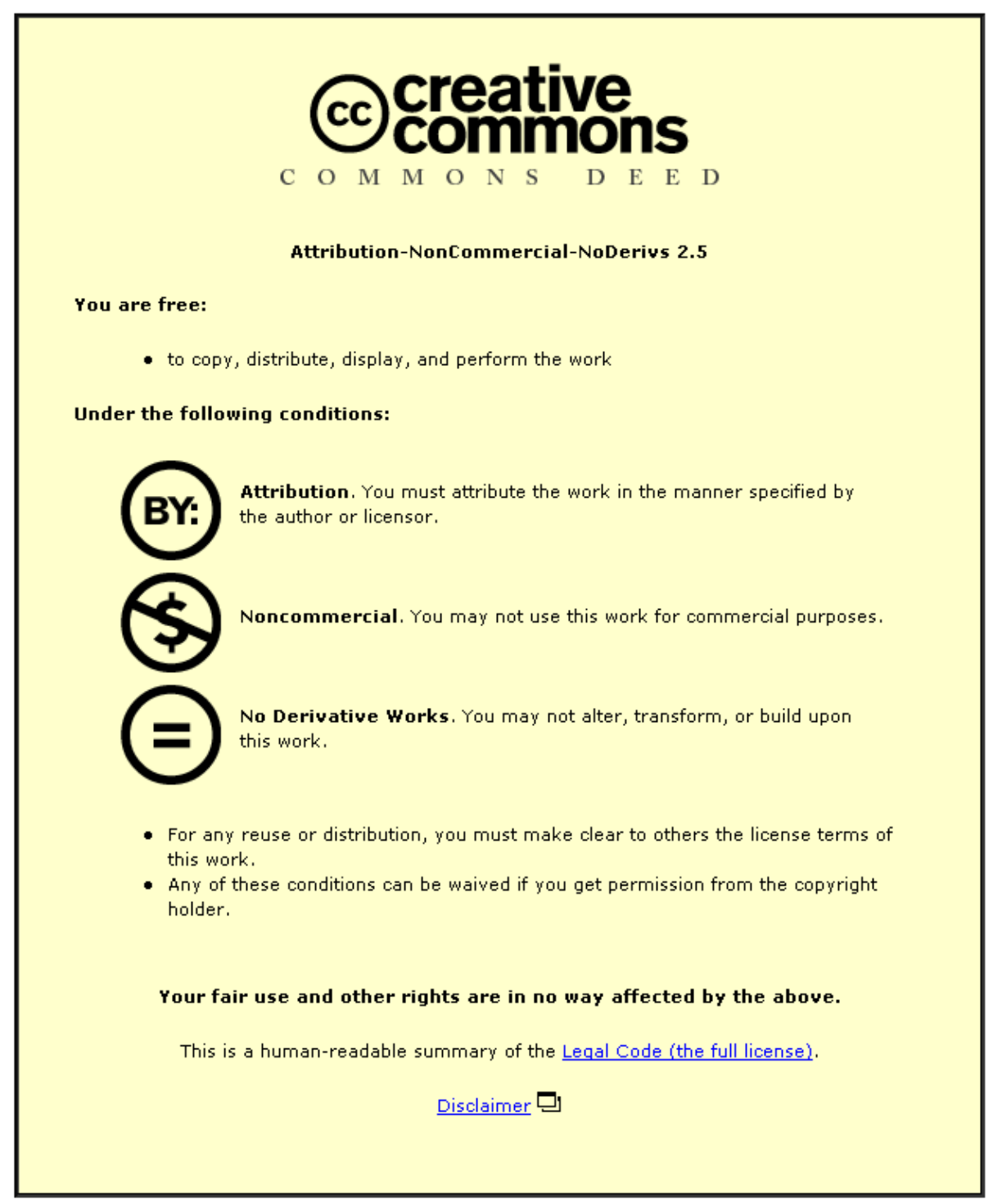

For the full text of this licence, please go to: http://creativecommons.org/licenses/by-nc-nd/2.5/ 


\title{
The Effect of the London Congestion Charge on Road Casualties: An Intervention Analysis
}

\author{
Robert B. Noland ${ }^{1}$ \\ Mohammed A. Quddus ${ }^{2}$ \\ Washington Y. Ochieng ${ }^{1}$ \\ ${ }^{1}$ Centre for Transport Studies \\ Department of Civil and Environmental Engineering \\ Imperial College London \\ LONDON SW7 2AZ \\ ${ }^{2}$ Transport Studies Group \\ Department of Civil and Building Engineering \\ Loughborough University \\ Leicestershire, LE11 3TU \\ United Kingdom \\ Email: m.a.quddus@lboro.ac.uk
}

Revised: 24 May, 2007 


\section{Abstract}

The introduction of the congestion charge in central London on the $17^{\text {th }}$ of February, 2003, led to a reduction in congestion. One factor that has not been fully analysed is the impact of the congestion charge on traffic casualties in London. Less car travel within the charging zone may result in fewer traffic collisions, however, as the number of pedestrians, cyclists, and motorcyclists increased after the introduction of the congestion charge, the number of traffic casualties associated with these groups may also have increased. Reductions in congestion can also lead to faster speeds. Therefore, there could be increases in injury severity for those crashes that do occur. An intervention analysis was conducted to investigate the effect of the congestion charge on traffic casualties for motorists, pedestrians, cyclists, and motorcyclists, both within the charging zone and in areas of London outside the zone. This was done for killed and serious injuries (known as KSI in British terminology) and for slight injuries to examine whether there were any shifts in severity outcomes. Our results suggest no statistically significant effect for total casualties in London, but within the charging zone there has been a statistically significant drop in motorist casualties, and possibly an increase in cyclist casualties. There is an associated effect of an increase in casualties of motorcyclists and cyclists in some areas outside the charging zone, suggesting that changes in the design of the congestion charge may be needed to achieve reductions in casualties. 


\section{INTRODUCTION}

In February 2003 an area-based congestion charging scheme was implemented in the central area of London. This scheme has attracted widespread attention throughout the world for its ambitious attempt to relieve congestion in a centralized urban area, as well as the political risks associated with implementing a charging scheme. In its first assessment, Transport for London (TfL, 2003) estimated that car movements decreased by about $30 \%$ and van and lorry movements by about $10 \%$ within the charging zone and overall traffic entering the charging zone was reduced by $18 \%$. At the same time movement of other modes have increased, in particular motorcycles (6\%), and bicycles (28\%) between Spring 2002 and Spring 2003, after the scheme was implemented (TfL, 2006).

The most recent assessment based on 2005 data, finds that there was a small further decrease in traffic entering the charging zone of about 3\%, attributable to an increase in the charge (TfL, 2006). Bicycle traffic has increased further but shows some signs of stabilizing, but the large initial increases in motorcycles have declined slightly by about 12\% between 2004 and 2005 . The monitoring report suggests that most of the changes since initial introduction of the scheme are not statistically significant (TfL, 2006).

Average traffic speeds increased initially from $13 \mathrm{~km} / \mathrm{h}$ to $17 \mathrm{~km} / \mathrm{h}$, translating into a reduction in congestion delay of up to $30 \%$ ( $\mathrm{TfL}, 2003$ ). Overall congestion reductions have remained at about 30\%, however, delay in all of Inner London has increased slightly to $1.5 \mathrm{~min} / \mathrm{km}$ from 1.3 $\mathrm{min} / \mathrm{km}$. TfL (2006) attributes this to other changes in the network which have reduced motorvehicle capacity (such as providing for bicycles and pedestrians). Within the charging zone delay has reduced to $1.7 \mathrm{~min} / \mathrm{km}$ from $2.3 \mathrm{~min} / \mathrm{km}$. Introduction of the scheme was concurrent with large increases in the number of buses throughout London to further encourage use of public transport without overburdening the rail and underground systems which are largely already at capacity during peak hours. Morning peak-hour bus patronage for passengers entering central London has increased by about one-third since charging was introduced (TfL, 2006).

Vehicles present within the charging zone between 7:00 and 18:30, Monday to Friday, are charged $£ 5$ ( $£ 8$ from July 2005, about US\$8.75 and US\$14.00 at Oct. 2005 exchange rates). Figure 1 displays a map of the charging zone. ${ }^{1}$ Residents of the zone receive a 90\% discount.

\footnotetext{
${ }^{1}$ In February 2007, the charging zone was further extended to the west.
} 
Exemptions are granted to environmentally friendly vehicles (battery powered or hybrid cars), motorcycles, vehicles owned by disabled drivers (Blue Badge holders), taxis, buses and certain other categories deemed to be essential. Charges are assessed only once per day, thus vehicles may enter or leave the zone freely without incurring additional charges.

The introduction of the congestion charge was also postulated to reduce traffic casualties. ${ }^{2}$ TfL (2006) has estimated that that there has been an overall reduction of about 40-70 casualty crashes during the charging hours within the charging zone (including the Inner Ring Road which forms the boundary of the zone). TfL's analysis was based on comparing the number of accidents for the 12 months after the introduction of charging with the same period before. The reduction in accidents was about $4 \%$ outside the charging hours and there has also been a reduction of about $7 \%$ in the rest of London. From this TfL suggests there has been about a 2-5\% reduction in casualties attributable to the congestion charging scheme and that this has persisted (TfL, 2005; TfL, 2006). They also report no detrimental changes associated with vulnerable road users within the charging zone, an issue that this paper examines explicitly (TfL, 2006).

Less car travel within the charging zone may result in fewer traffic collisions. On the other hand, reducing congestion can lead to faster travel speeds that may increase the risk of more severe traffic collisions (Shefer \& Rietveld, 1997). There is evidence in the literature to support this hypothesis, for example Zhou \& Sisiopiku (1997) and Ivan et al. (2000). However, these studies did not examine urban roads where even uncongested traffic speeds are still relatively low (for example London has a $30 \mathrm{mph}$ speed limit on most roads). Noland \& Quddus (2005) examined the London region in an attempt to disentangle the factors associated with congestion but found no conclusive effects linking reductions in proxies for congestion with increased severity of crashes.

The shifting of traffic to other roads immediately outside the charging zone may also have some effects on casualties. However, TfL has estimated that there have not been substantive changes in traffic levels in these areas. The relative number of casualties may also be sensitive to the mix of modes within the charging area. In particular, increases have occurred in the number of more vulnerable road users (pedestrians, cyclists, and motorcyclists). One could argue that this would result in increased traffic casualties associated with these more vulnerable groups.

\footnotetext{
${ }^{2}$ Traffic casualties include only those crashes where there was a fatality or an injury to a person.
} 
While TfL conducted a simple before and after comparison to conclude that casualties have decreased, our objective is to examine the effects in more detail (TfL, 2003). TfL (2006) reports some more detailed results that find reductions within the charging zone, but do not seem to analyze system-wide effects. Many other factors have an impact on casualties, such as overall economic activity. Controlling for overall trends over time is needed to statistically examine the impact of the congestion charge.

The ordinary student t-statistic may not be appropriate to examine any changes in the mean level of a time series following an intervention. This is because the simple t-test is valid only if the observations before and after the intervention varied about their means both normally with constant variances and independently (Box and Tiao, 1975). Because of seasonality, randomness, and trends in the time series of traffic casualties, the successive observations may be serially correlated and the series then becomes a non-stationary ${ }^{3}$ time series. This makes an ordinary t-test invalid for this type of analysis. Box and Tiao (1975) developed a time-series modelling technique that can take into account both trend and seasonality effects normally found in a timeseries dataset. This technique is known as an autoregressive integrated moving average (ARIMA) model. Tiao et al. (1975) extended the ARIMA model to quantify the impacts of any interventions on the mean level of a time-series. This stochastic modelling technique is known as an intervention analysis (Box and Tiao, 1975; Tiao et al., 1975; Wichern and Jones, 1977). ${ }^{4}$

The Box-Tiao intervention analysis has been applied in various fields over the last few years. For example, Goh (2005) used it to analyze the impact of construction demand and tender price levels on the Asian financial crisis, Sharma and Khare (1999) for the impact of air pollution control laws on CO concentration, Zimring (1975) for the impact of gun control laws on crimes, and of most relevance to this work, Houston and Richardson (2002) and Bhattacharyya and

\footnotetext{
${ }^{3}$ A stochastic process is said to be non-stationary if its mean and variance are not constant over time and the value of the covariance between two time periods depends on the actual time at which the covariance is computed.

${ }^{4}$ Another approach for examining before and after effects is the Empirical Bayes method, as promoted by Ezra Hauer (see for example, Hauer et al., 2002). Other approaches that use data that varies over time are based on annualized data, allowing panel data techniques to be used (see, for example, Miaou et al. (2003) and Noland (2003)). Noland and Karlaftis (2005) compare some of these methods and highlight the potential problems with controlling for serial correlation. Our data is not suited for use with panel methods, as it is a monthly time-series, requiring trend and seasonal adjustments.
} 
Layton (1979) for the impact of seat belt legislation on traffic safety, and Rock (1995) on the impact of an increase in speed limits to $65 \mathrm{mph}$.

The primary objective of this paper is to investigate whether the introduction of the congestion charge on the $17^{\text {th }}$ of February 2003 has had any effect on traffic casualties in London and to examine the effect on vulnerable road users. The Box-Tiao intervention method is used to examine these hypotheses. This paper is organised as follows. The next section describes the data sources used for this analysis in some detail. The intervention method used for the analysis is then discussed followed by a presentation and interpretation of the results. Conclusions and policy implications are then presented.

\section{DATA}

Data on traffic casualties was available from January 1991 to November 2004. This data was obtained from the STATS19 database (1991-2002) and Transport for London (2003-2004). ${ }^{5}$ Data for only the London region (i.e., the 33 London Boroughs) was used. This was further classified based on three zones - the congestion charging zone (including casualties on the Inner Ring Road which forms the zones boundary), Inner London (excluding the charging zone), and Outer London. These areas are shown in Figure 2. Data was further aggregated into monthly totals, giving a total of 167 observations points for each of the three spatial units, as defined above.

Within the zone in which the congestion charging applies a total of 4229 killed and seriously injured (KSI) casualties were recorded over the 14 years (1991-2004) of data within our time series between 7:00am and 7:00pm (the congestion charging period plus 30 mins). Of these $7.2 \%$ of the KSI were car occupants, $14.2 \%$ were cyclists, $24.8 \%$ were motorcyclists, and $41.5 \%$ were pedestrians. Within Inner London (excluding the congestion zone) the percentages during the charging period were found to be 19.8\% (car), 11.8\% (cyclists), 20.1\% (motorcyclist), and 38.8\% (pedestrians). In Outer London, during the same peak (congested) period, the percentages were 39.1\% (car), 8.0\% (cyclists), 14\% (motorcyclists), and 29.8\% (pedestrians). The proportion of peak period KSI due to cyclists, motorcyclists, and pedestrians are higher in the congestion charging zone compared to other areas of London. A higher percentage of peak-period KSI casualties from car occupants were found in Outer London.

\footnotetext{
${ }^{5}$ Transport for London supplies the London data for the STATS19 database. We obtained the data direct from TfL only because 2003-04 data had not yet been incorporated in STATS19.
} 
Figure 3 shows a monthly time series plot of all KSI casualties within the congestion charging zone over the last 14 years between 7:00am and 7:00pm (the congestion charging period plus 30 mins). The introduction of the congestion charge (1 $17^{\text {th }}$ February 2003), which is the intervention in our analysis, is also highlighted within the plot. This plot shows both seasonal fluctuations and overall trends in the data. Casual analysis of this graph suggests that overall KSI casualties dropped after the intervention.

\section{METHODOLOGY}

The hypothesis of this study is that the introduction of the congestion charge in central London does not have any effect on traffic casualties. If this hypothesis is to be rejected then the nature and magnitude of such effects need to be estimated. Given that time series data (about 14 years) of traffic casualties is available for London, an intervention analysis is one method to test the above hypothesis. As discussed, the intervention analysis can be used to investigate the impact of any event on a particular time series. The intervention model proposed by Box and Tiao (1975) is used to analyze the effect of the congestion charge on traffic casualties. The model takes the following form:

$$
y_{t}=f(I, X)+N_{t}
$$

in which $t$ is the discrete time (e.g., week, month, quarter, or year), $y_{t}$ is the appropriate Box-Cox transformation of $Y_{t}$, say $\ln Y_{t}, Y_{t}^{2}$, or $Y_{t}$ itself (Box and Cox, 1964), $Y_{t}$ is the dependent variable for a particular time $t, f(\boldsymbol{I}, \boldsymbol{X})$ is the dynamic part of the model which contains the intervention component (I) and the deterministic effects of independent control variables $(\boldsymbol{X})$, and $\boldsymbol{N}_{\boldsymbol{t}}$ is the stochastic variation or noise component. Both the noise and intervention components are discussed below.

\section{Noise component $\left(N_{t}\right)$ :}

Box and Tiao (1975) suggest that the purely random component $\left(\boldsymbol{N}_{t}\right)$ follows a seasonal autoregressive integrated moving average (SARIMA) model that is normally denoted as SARIMA $(p, d, q) \times(P, D, Q)_{S}$ model in which $p$ is the order of the non-seasonal autoregressive (AR) process, $P$ is the order of the seasonal AR process, $d$ is the order of the non-seasonal difference, $D$ 
is the order of the seasonal difference, $q$ is the order of the non-seasonal moving average (MA) process, $Q$ is the order of the seasonal MA process, the subscript $s$ is the length of seasonality (for example $s=12$ with monthly time series data). The SARIMA model can be expressed as (Box et al., 1994):

$$
\phi(B) \Phi\left(B^{s}\right)(1-B)^{d}\left(1-B^{s}\right)^{D} N_{t}=\theta(B) \Theta(B) u_{t}
$$

in which $\phi$ and $\Phi$ are the regular and seasonal AR operators, $\theta$ and $\Theta$ are the regular and seasonal MA operators, $B$ and $B^{s}$ are the backward shift operators, and $u_{t}$ is an uncorrelated random error term with zero mean and constant variance $\left(\sigma^{2}\right)$. Details can be found in Box et al. (1994) for further explanation of this model.

\section{Intervention function $f(I)$ :}

A number of intervention functions are used to examine the impact of an intervention in time series data (Box and Tiao, 1975; Jorquera et al., 2000). In our case, the impact of the congestion charge on traffic casualties is the intervention. The intervention causes an immediate effect on traffic in central London and in this case is permanent. Therefore, a step function can be used to define such an intervention as:

$$
f\left(I_{t}\right)=\varpi_{0} I_{t}
$$

where $\varpi_{0}$ is a constant, and $I_{t}$ is the intervention variable which takes a value of 0 for every month before the implementation date of the congestion charge and a value of 1 for every month thereafter, i.e.,

$$
I_{t}=\left\{\begin{array}{lc}
1 & \text { for } t \geq t^{\prime} \\
0 & \text { elsewhere }
\end{array}\right.
$$

Then equation (3) becomes

$$
f\left(I_{t}\right)=\left\{\begin{array}{cc}
0 & \text { for } t<t^{\prime} \\
\varpi_{0} & \text { for } t \geq t^{\prime}
\end{array}\right.
$$


and, the general intervention model takes the following form:

$$
y_{t}=\varpi_{0} I_{t}+\boldsymbol{\beta} \boldsymbol{X}+\frac{\theta(B) \Theta(B) u_{t}}{\phi(B) \Phi\left(B^{s}\right)(1-B)^{d}\left(1-B^{s}\right)^{D}}
$$

The basic strategy of intervention analysis is to identify a SARIMA model (noise component) before the intervention as shown in equation (2). This includes the identification of model parameters $p, d, q, P, D$, and $Q$ using the autocorrelation function (ACF) and the partial autocorrelation function (PACF). The next step is to add intervention variables (usually dummy variables) that represent the timing of the intervention. Some other independent variables (usually control variables) can also be added. Proper training of the time-series process should account for most confounding factors and the addition of too many explanatory variables may also create specification problems, primarily high levels of collinearity between contemporaneous trends (Rock, 1995). Bhattacharyya and Layton (1979) point out that not controlling for other factors also implies that the trend could lead to negative values on the dependent variable, which are not realistic. Their analysis includes petrol consumption as a control variable for road fatalities; in our case, we use all injury road crashes in London as our control variable (and in some models all motorcycle injury crashes). ${ }^{6}$

The final step is to re-estimate the model (as shown in equation (5)) including both intervention and control variables for the entire time series with the model parameters identified previously in the pre-intervention model. The statistical significance of the intervention variables (in our case $\varpi_{0}$ ) explains whether the intervention has any effect on the time series and the magnitude of their coefficients measures the substantive effect of the intervention.

\section{Other Estimation Issues}

Two additional issues need to be considered when analyzing accident data. One is that the data typically follows a Poisson distribution and thus may not be normally distributed. Count regression methods, such as Poisson or negative binomial (NB) models, are typically used to estimate cross-sectional and panel accident data (Lord et al., 2005). NB models are a generalization of the Poisson model that can account for over-dispersion (Miaou, 1994; Shankar

\footnotetext{
${ }^{6}$ Other possible control variables included total passenger cars and gross-value added (GVA) for London; however, these were only available in quarterly time-series and were also highly correlated with the total crashes within London.
} 
et al., 1995). Although the source of over-dispersion in accident data cannot be distinguished, its presence can be adjusted by introducing a stochastic component in the log-linear relationship between the expected numbers of accident in an observation unit $t\left(y_{t}\right)$ and the covariates $X$. This becomes more problematic with simple time-series data, as is the case with our analysis. However, a time trend variable can be used to control for serial correlation in the data. Such an NB model can be expressed as:

$$
\ln y_{t}=\beta X_{t}+\varpi_{0} I_{t}+\varepsilon_{t}
$$

In this model, the variation in $y_{t}$ is due to both to variation in $X$ and $I_{t}$ but also due to unobserved heterogeneity introduced by $\varepsilon_{t}$. The probability density function (pdf) for the NB distribution can be expressed as (Cameron and Trivedi, 1998):

$$
\operatorname{Pr}\left(N_{t} \mid y_{t}, k\right)=\frac{\Gamma\left(N_{t}+(1 / k)\right)}{\Gamma\left(y_{t}+1\right) \Gamma(1 / k)}\left(\frac{1 / k}{(1 / k)+y_{t}}\right)^{1 / k}\left(\frac{y_{t}}{(1 / k)+y_{t}}\right)^{N_{t}}
$$

where, $k(\geq 0)$ is often referred to as the overdispersion parameter.

Integer Autoregressive (INAR) techniques are one approach to deal with both count data and time-series effects (Brännäs and Hellström, 2001). These techniques introduce additional estimation complexities. We explored the use of INAR for this analysis and found no major differences in results; some models, however, did not converge properly making a full comparison not possible.

To further explore whether a count data model is appropriate, and to test the robustness of our results, we estimated parallel negative binomial regression models, including a time trend in each. We also tested whether our data was normally distributed. The residuals in most of our ARIMA models are normally distributed, with two exceptions. These are for the car KSI and cyclist KSI models within the congestion charging zone, where data is sparser than for Inner and Outer London; the results on these specific models are discussed further below. The central limit theorem suggests that large values should approach the normal distribution, and this likely explains the finding that the data is normally distributed (total casualties per month range from about 2000 to 3500 over the time-series). 
A common criticism of many traffic safety studies is "regression to the mean", or endogeneity bias. That is, many interventions to deal with a safety problem are implemented because of a safety problem. Estimates examining these sort of interventions can often be biased. We do not see this as an issue in this analysis, as the congestion charge in central London was not implemented due to any safety issue but due to congestion.

\section{RESULTS}

The main objective of the analysis was to test whether the introduction of the congestion charge in central London has had any effect on traffic casualties. Our strategy is to analyze the effect of the intervention during the time period that the charging is in effect and for all time periods; for car occupants and vulnerable road users (pedestrians, cyclists and motorcyclists) and all modes combined; and, for the three spatially distinct areas of London, the congestion charging zone, Inner London (without the congestion charging zone), and Outer London. Models for KSI and slight injuries are estimated in all cases. The number of fatalities was low in any given month and often zero, therefore we combine fatalities and serious injuries into KSI. ${ }^{7}$

The charging period is from 7:00am to 6:30pm. It has been found that there is a slight increase in traffic within the charging zone just after the charging period ends (TfL, 2003). TfL uses 7:00am to $7: 00 \mathrm{pm}$ in determining their casualty counts, therefore, we also use this as our effective time period for representing the charging period in our analysis.

The two main components of the models are the intervention variable, which is the introduction of the congestion charge, and the seasonal ARIMA parameters. In addition to these parameters an additional control variable is included which is the monthly total of all casualty crashes for all of London. This serves as a control for overall trends in crash levels in London and accounts for other effects and safety policies implemented over the time trend of the data (e.g. the introduction of speed cameras, changes in safety-belt usage or other changes in safety and enforcement policy). ${ }^{8}$

\footnotetext{
${ }^{7}$ The use of total KSI as the dependent variable allows us to evaluate the policy impact most effectively. We are not seeking to evaluate just crashes but their impact, which is most important if one is concerned with the costs and benefits of a policy intervention.

${ }^{8}$ These other factors are not included in our models for two reasons. First, we do not have detailed data on how these have changed over the time period in question. Second, inclusion of these variables are not necessary since the ARIMA process controls for confounding factors; making the model more complex can actually introduce additional specification problems, such as regression to the mean, or collinearity between effects and trends.
} 
Tables 1-6 show results for a total of 48 intervention models, disaggregated by time period, area of London, mode of transport, and severity of the casualty (note that pedestrian models are omitted as we found no significant effect on pedestrian casualties from the intervention). For each of the intervention models, the appropriate seasonal ARIMA model was estimated for the pre-intervention period between January 1991 and January 2003. This gives a total of 145 observations. This can best be explained by examining one of the results, for example in Table 1a the model for motorcyclist KSIs during the charging period results in a SARIMA $(1,1,1) \times(1$, $1,1)_{12}$ model. This means that this time series data requires one non-seasonal $(d=1)$ and one seasonal $(D=1)$ difference to obtain a stationary time series. This SARIMA $(1,1,1) \times(1,1,1)_{12}$ model consists of four parameters, namely, a first order non-seasonal AR(1), a first order nonseasonal, MA(1), a first order seasonal, SAR(1), and finally a first order seasonal, SMA(1). The ACF and PACF functions of the series and the residuals, and the modified Box-Pierce (LjungBox) Chi-Square statistic are used to identify these parameters. Therefore, the intervention model for this time series data comprises the intervention variable (congestion charging, CC), the SARIMA parameters (AR(1), MA(1), SAR(1), and SMA(1)), and the control variable which is total monthly traffic casualty crashes within Greater London. The original series length becomes 167 with a residual of 154 as 13 observations are lost because of one regular and one seasonal differencing. Most of the other intervention models have the noise component in the form of SARIMA $(0,1,1) x(0,1,1)_{12}$ and relevant statistics are included in all Tables.

The intervention variable associated with the introduction of the congestion charge is found to have variable effects depending on the time period, mode, and area of London. Tables 1a and 1b examine the effect within the congestion charging zone and only during the charging period. Total KSI and slight injuries show no statistically significant effect in these cases. There is a small effect associated with casualties for car occupants, at the 85\% confidence level for KSI and $90 \%$ for slight injuries. No effect is found for motorcyclists and cyclists. Extending the analysis to all time periods (Table 2a) we see a similar negative effect for slight injuries of car occupants (at 95\% confidence level), but not for KSI. This broadly confirms the conclusions of TfL as to the effectiveness of reducing car occupant casualties within the charging zone.

Shapiro-Wilk normality tests applied to the residuals suggest that the car occupant model and the cyclist models in Tables 1 and 2 violate the normality assumption (Shapiro and Wilk, 1965). Of all the models estimated, these are the only two that violate this assumption. Therefore, we 
estimate equivalent negative binomial models in Tables $1 \mathrm{~b}$ and 2b (Lord et al., 2005). Poisson regressions were also examined, but were rejected in favor of the Negative Binomial model. This is common in crash data as the Poisson regression assumes the mean is equal to the variance, but this is typically violated. The level of statistical significance in the negative binomial model results is higher for the car occupant model and there is a negative and significant effect for all slight injuries, however, there is a positive effect for cyclists. The corresponding NB model for all time periods (Table 2b) shows a similar effect of an increase in cyclist casualties (both KSI and slight injuries) associated with the congestion charge.

TfL (2003) suggests that there has been about a 2 to 5 percent reduction in casualty crashes within the congestion zone (including the Inner Ring Road). In the year immediately preceding implementation of the congestion charge there were 1868 crashes involving casualties (and 1992 casualties) within this zone. Our analysis suggests a reduction of about 68 casualties per year ${ }^{9}$ or a drop of 3.4\% compared to the prior year, which is within the range reported by TfL (based on the model in Table 1a). Cyclists entering the charging zone have likely increased and while the ARIMA model does not detect any effect, we do find an increase in cyclist casualties within the congestion zone. Given the violation of the normality assumption, this might be a better specification for the cyclist model.

Tables 3 and 4 show estimated models for the Inner London zone (excluding the congestion charging zone). While overall casualties show no effect from the congestion charge, there is a positive and significant effect associated with motorcycle casualties. Both KSI and slight injuries increase during the charging period, while slight injuries show a large and significant increase (40 per month, or about a $16 \%$ increase) for all time periods. One of the impacts of the charging scheme has been to increase the number of commuters on motorcycles, as motorcycles within the charging zone have increased by 15\%. This suggests that the risks of motorcycles have not changed as the total increase in casualties is broadly consistent with this at a $16 \%$ increase.

While these results show no effect on motorcycle casualties within the charging zone, the increase in casualties in the Inner London zone suggests these may be occurring on trips to the charging zone. Figure 4 displays the locations of all crashes with a motorcycle casualty within Inner London, after implementation of the congestion charge. While it is impossible to know the

\footnotetext{
${ }^{9}$ Based on adding the coefficients for slight injuries and KSI $(4.7+0.9=5.6)$ which give a monthly reduction and multiplying by 12 .
} 
destinations of the motorcyclists, it is clear from visual observation that the majority of crashes occurred on radial roads leading to the central area of London. This should not be too surprising as these roads have the largest flows of traffic. It is also possible that overall motorcycle ownership and usage increased in response to the implementation of congestion charging, even if those purchasing motorcycles do not make regular trips to the central area. ${ }^{10}$

While motorcycle casualties in Inner London seem to have increased after implementation of the congestion charge no similar effect is found for bicycle casualties. This is despite an increase in bicycle usage within the congestion charging zone.

Our analysis of effects within Outer London (Tables 5 and 6) show no effect on overall casualties during the congestion charge, but a large and statistically significant drop in slight injuries during all time periods at the $90 \%$ confidence level (Table 6). While traffic effects due to the congestion charge are probably minor within Outer London, this effect appears to be due to the intervention. There is an increase in slight motorcyclist injuries and bicyclist KSI's during the charging period (Table 5). This could be due to shifts in mode spurred by the congestion charge. While it is unlikely that many bicyclists will commute from Outer London to the congestion zone, there may have been increased use of bicycles to access Underground and commuter rail stations, during peak hours.

The control variable, which is the natural logarithm of total monthly crashes with casualties in London, is found to be statistically significant in most of the intervention models estimated. As anticipated, the magnitude of the coefficient of this variable is always larger in the slight injury models than in the KSI models, as more severe injuries are likely affected by other factors which are not controlled for. It tends to be less significant for some of the bicyclist models, suggesting that other safety policies have less association with bicycle casualties, which is not an unexpected result.

While the control variable is generally significant and positively associated with motorcycle casualties, it is possible that general reductions in road casualties from specific policy initiatives will be less associated with motorcycle casualties. For this reason we also re-estimate the motorcycle casualty models for each area with the control variable replaced by the logarithm of

\footnotetext{
${ }^{10}$ For example, see the following website from Honda motorcycles after the increase in the congestion fee to £8: http://www.honda.co.uk/news/motorcycles/20050727.html (accessed 24-May-2007).
} 
total motorcycle casualty crashes (Table 7). For the models of the congestion charging zone, the value of this parameter is larger than in the previous models; however, in the models for Inner and Outer London, the value is less. This suggests that it may be picking up more of the variation of external factors within the congestion charging zone than in the Inner and Outer London zones. Interestingly we find that for all time periods there is now a statistically significant (at the $90 \%$ level) drop in slight motorcycle injuries within the charging zone.

The Outer London models now show no statistically significant effect while the models for Inner London show a diminished effect; there is a smaller increase of 19 slight injuries a month for all time periods (compared to 40 previously). There is now no positive and significant effect during the charging period.

While it is not possible to definitively say which model is superior, the log-likelihoods of the models in Table 7 are generally larger than the corresponding models with the original control variable (the one exception being both models for Outer London during all time periods). This would suggest that slight motorcycle injuries probably increased somewhere between 20 and 40 per month, due to implementation of the congestion charge. While there is a slight decrease of 5.6 car occupant casualties within the charging zone each month, the overall effect was not statistically significant within Inner London and within the congestion charging zone. We did detect a total reduction in casualties after implementation of the charge within the Outer London area, but this is much less likely to be attributable to the congestion charge. There is also evidence that cyclist casualties within the charging zone increased.

\section{CONCLUSIONS}

This analysis suggests that the safety impacts of the London congestion charge are not conclusively beneficial and that more detailed analysis of modal and system-wide impacts can give differing results. While results suggest a decrease in car occupant casualties within the congestion charging zone, no significant overall effects could be detected within Inner London or within the congestion charging zone, but some reduction in car occupant slight injuries in Outer London. Total casualties also show no significant change within the charging zone. The reduction in car occupant casualties also suggests that changes in severity levels from changes in relative speeds, had no effect. 
Our analysis suggests, however, that there have been increases in motorcycle casualties within Inner London and possibly increases in cyclist casualties within the charging zone. This could clearly be a result of the incentive to use motorcycles which do not pay the congestion charge and overall increases in bicyclists. TfL data has shown an increase in motorcycle trips within the charging zone of about $15 \%$. We speculate that increases in bicycle casualties in the Outer London zone may be due to increased commuting, perhaps to rail and underground stations.

The recent increase in the congestion charge to £8 per day could increase the incentive for some commuters to shift to motorcycles. This will offer the opportunity for further analysis once data are available, as will the extension to west London implemented in Feb. 2007. However, these results do suggest a potential problem and one solution is to also charge motorcyclists who enter the congestion zone. Alternatively, strategies could focus on other policies that can increase the safety of motorcyclists and bicyclists in London.

\section{REFERENCES}

Bhattacharyya, M.N., Layton, A.P., 1979, Effectiveness of seat belt legislation on the Queensland road toll - an Australian case study in intervention analysis, Journal of the American Statistical Association, 74(367): 596-603.

Box, G.E.P., Cox, D.R., 1964, An analysis of transformations (with discussion). Journal of the Royal Statistical Society, Series B, 26, 211-246.

Box, G.E.P., Jenkins, G.M., Reinsel, G.C., 1994, Time series analysis: forecasting and control cliffs, 3rd ed. Prentice-Hall, Englewood Cliffs

Box, G.E.P., Tiao, G.C., 1975, Intervention analysis with applications to economic and environmental problems. Journal of the American Statistical Association 70, 70-74.

Brännäs, K., Hellström, 2001, Generalized integer-valued autoregression, Econometric Reviews, 20(4), 425-443.

Cameron, A. C., Trivedi, P.K., 1998, Regression analysis of count data, Cambridge University Press, New York.

Goh, B.H., 2005, The dynamic effects of the Asian financial crisis on construction demand and tender price levels in Singapore, Building and Environment, 40: 267-276.

Hauer, E., Harwood, D., Council, F.M., Griffith, M.S., 2002, Estimating safety by the empirical bayes method: A tutorial, paper presented at the $81^{\text {st }}$ Annual Meeting of the Transportation Research Board, Washington, DC. 
Houston, D.J., Richardson, L.E., 2002, Traffic safety and the switch to a primary seat belt law: the California experience, Accident Analysis and Prevention 34: 743-751

Ivan, John N., Wang, Chunyan, Bernardo, Nelson R., 2000, Explaining two-lane highway crash rates using land use and hourly exposure, Accident Analysis and Prevention 32: 787-795.

Jorquera , H., Palma, W., Tapia, J., 2000, An intervention analysis of air quality data at Santiago, Chile, Atmospheric Environment 34: 4073 - 4084.

Lord, Dominique, Simon P. Washington, and John N. Ivan, 2005, Poisson, Poisson-gamma and zero-inflated regression models of motor vehicle crashes: balancing statistical fit and theory, Accident Analysis and Prevention, 37: 35-46.

Miaou, S.P., 1994. The relationship between truck accidents and geometric design of road section: Poisson versus negative Binomial regression. Accident. Analysis and Prevention. 26 (4), 471-482.

Miaou, S.P., Song, J.J., Mallick, B.K., 2003, Roadway traffic crash mapping: a space-time modeling approach, Journal of Transportation and Statistics, 6(1): 33-57.

Noland, R.B., 2003, Traffic Fatalities and Injuries: The Effect of Changes in Infrastructure and Other Trends, Accident Analysis and Prevention, 35: 599-611.

Noland, R.B., and Karlaftis, M.G., 2005, Sensitivity of Crash Models to Alternative Specifications, Transportation Research E, 41: 439-458.

Noland, Robert, B. and Mohammed A. Quddus, 2005, Congestion and Safety: A Spatial Analysis of London, Transportation Research A, 39: 737-754.

Rock, Steven M., 1995, Impact of the 65 MPH speed limit on accidents, deaths, and injuries in Illinois, Accident Analysis and Prevention, 27(2): 207-214.

Shankar, V.N., Mannering, F., Barfield, W., 1995. Effect of roadway geometric and environmental factors on rural freeway accident frequencies. Accident. Analysis and Prevention. 27 (3), 371-389.

Sharma, P., Khare, M., 1999, Application of intervention analysis for assessing the effectiveness of CO pollution control legislation in India, Transportation Research D, 4: 427-432

Shapiro, S.S. and M.B. Wilk, 1965, An analysis of variance test for normality (complete samples), Biometrika, 52(3/4): 591-611.

Shefer, Daniel and Rietveld, Piet, 1997, Congestion and safety on highways: towards an analytical model, Urban Studies, 34(4): 679-692.

Tiao, G.C., Box, G.E.P., Harmming, W.I., 1975, Analysis of Los Angeles photochemical smog data: a statistical overview. Journal of the Air Pollution Control Association, 25: 260-268.

Transport for London (TfL), 2003, Congestion charging: Six Months On. Available on the internet at: http://www.tfl.gov.uk. Accessed January 10, 2003. 
Transport for London (TfL), 2005, Central London congestion charging scheme: impact monitoring, Available on the internet at: http://www.tfl.gov.uk. Accessed May 2005.

Transport for London (TfL), 2006, Central London Congestion Charging: Impacts Monitoring, Fourth Annual Report. Available on the internet at: http://www.tfl.gov.uk. Accessed May 2007.

Wichern, D.W., Jones, R.H., 1977, Assessing the impact of market disturbances using intervention analysis, Management Science, 24(3): 329-337

Zimring, F., 1975, Firearms and federal law: the Gun Control Act of 1968. Journal of Legal Studies 4, 2 (January): 133-198.

Zhou, M. and Sisiopiku, V., 1997, On the relationship between volume to capacity ratios and accident rates, Transportation Research Record 1581: 47-52. 


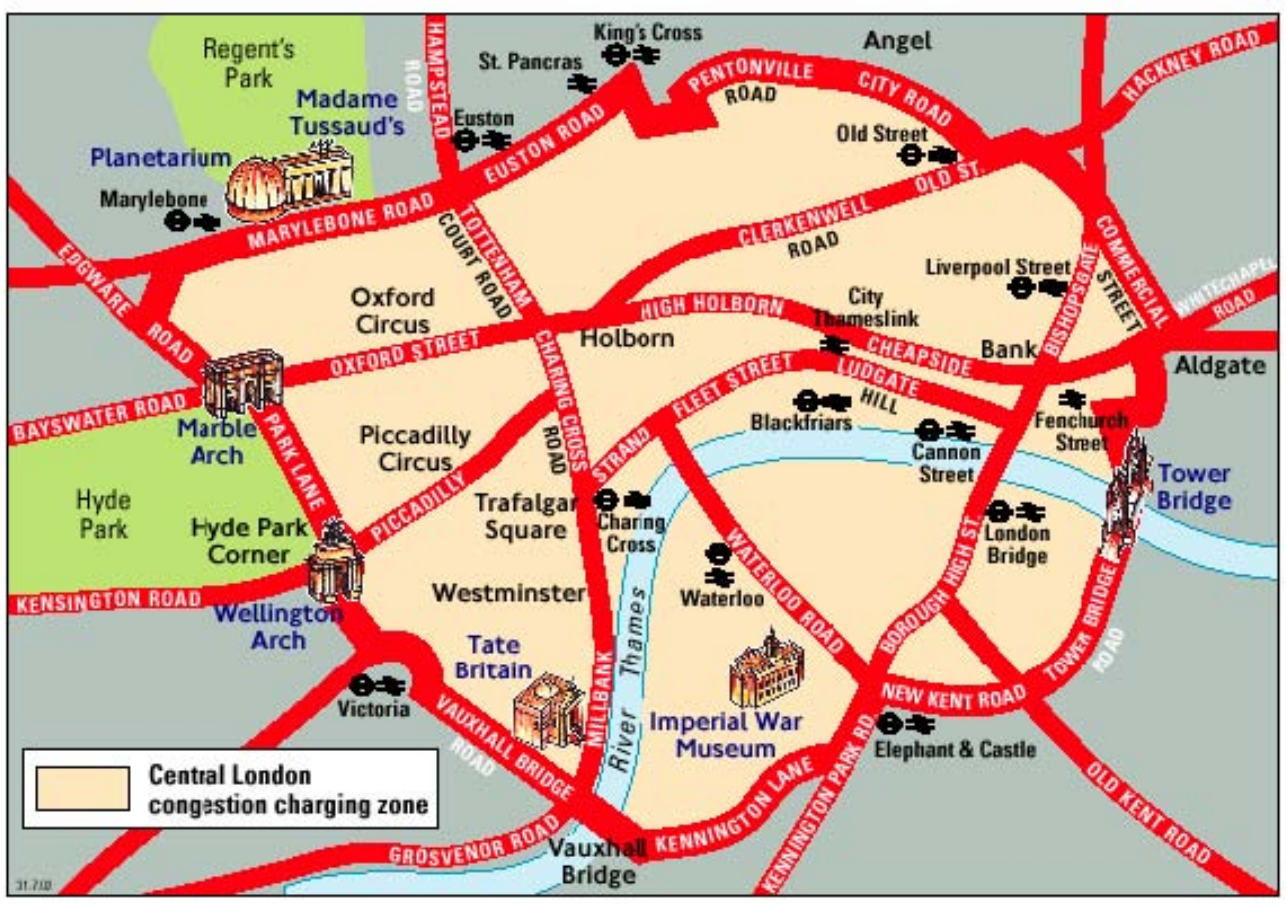

Figure 1

\section{London congestion charging zone}




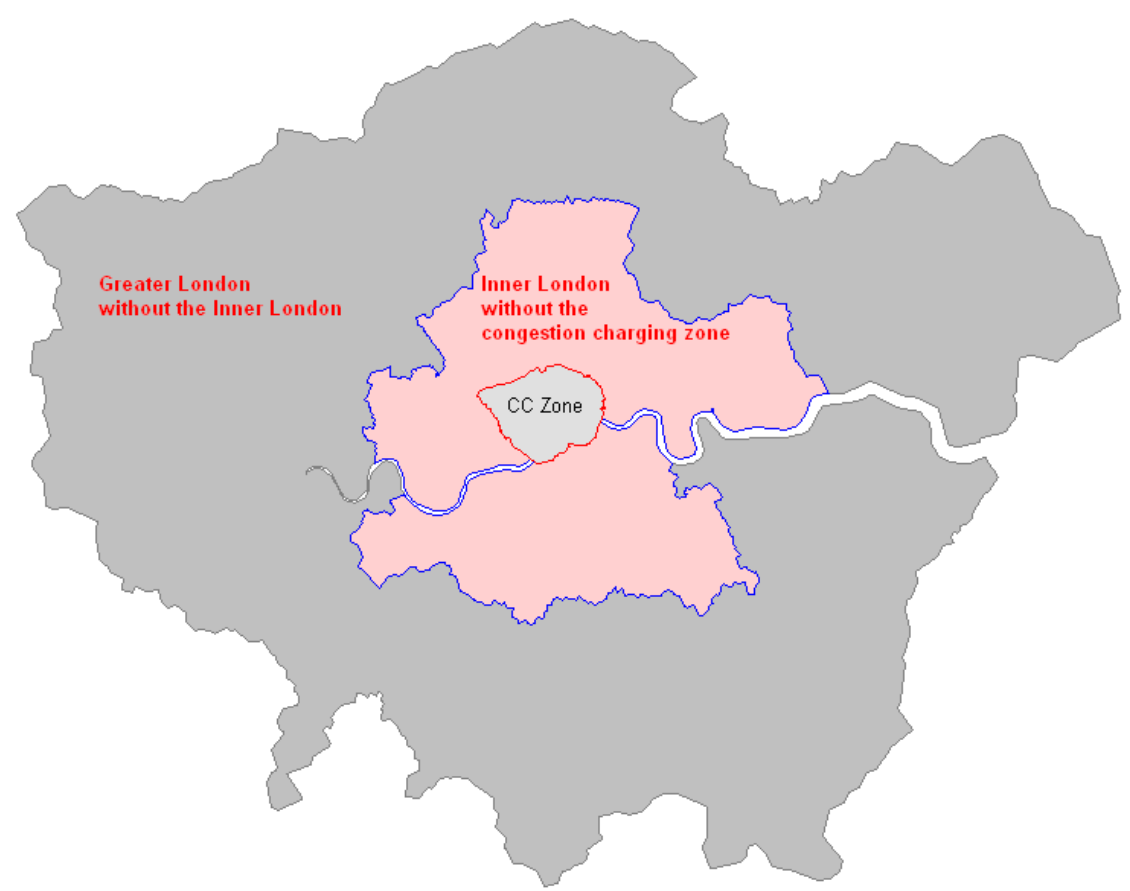

Figure 2

Areas of London used in the analysis 


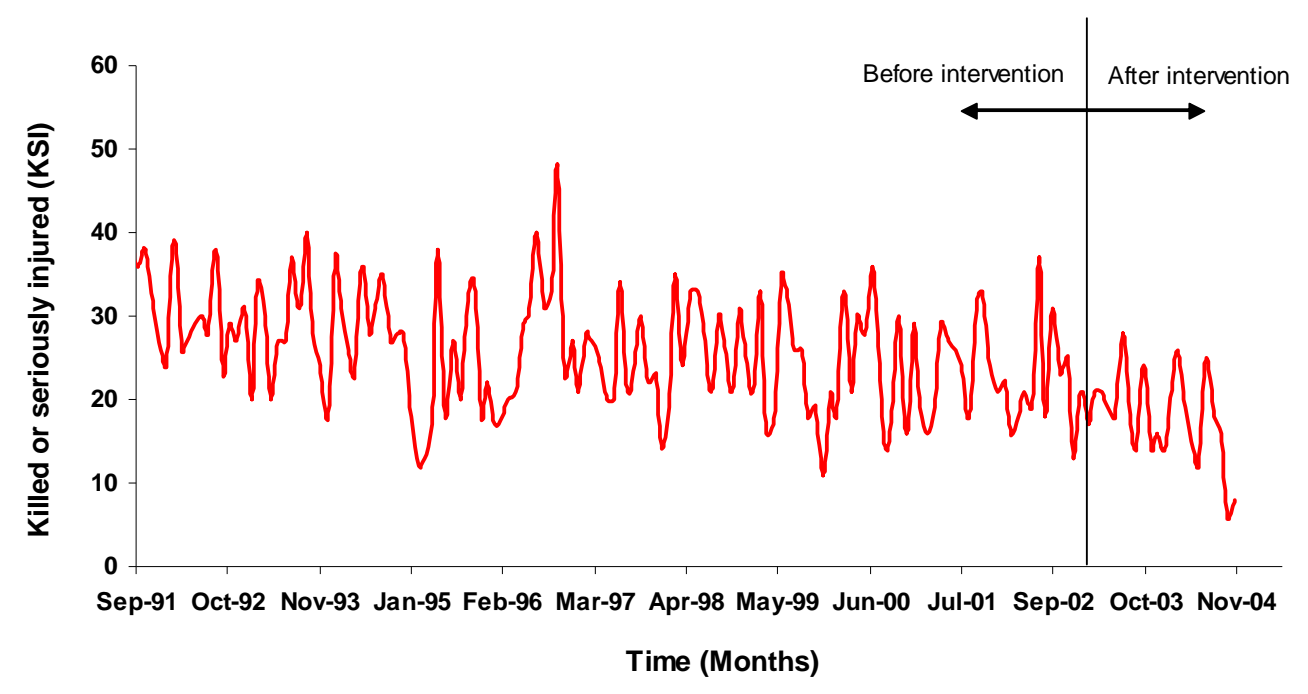

Figure 3

Total KSI during the charging period within the congestion charging zone boundaries 


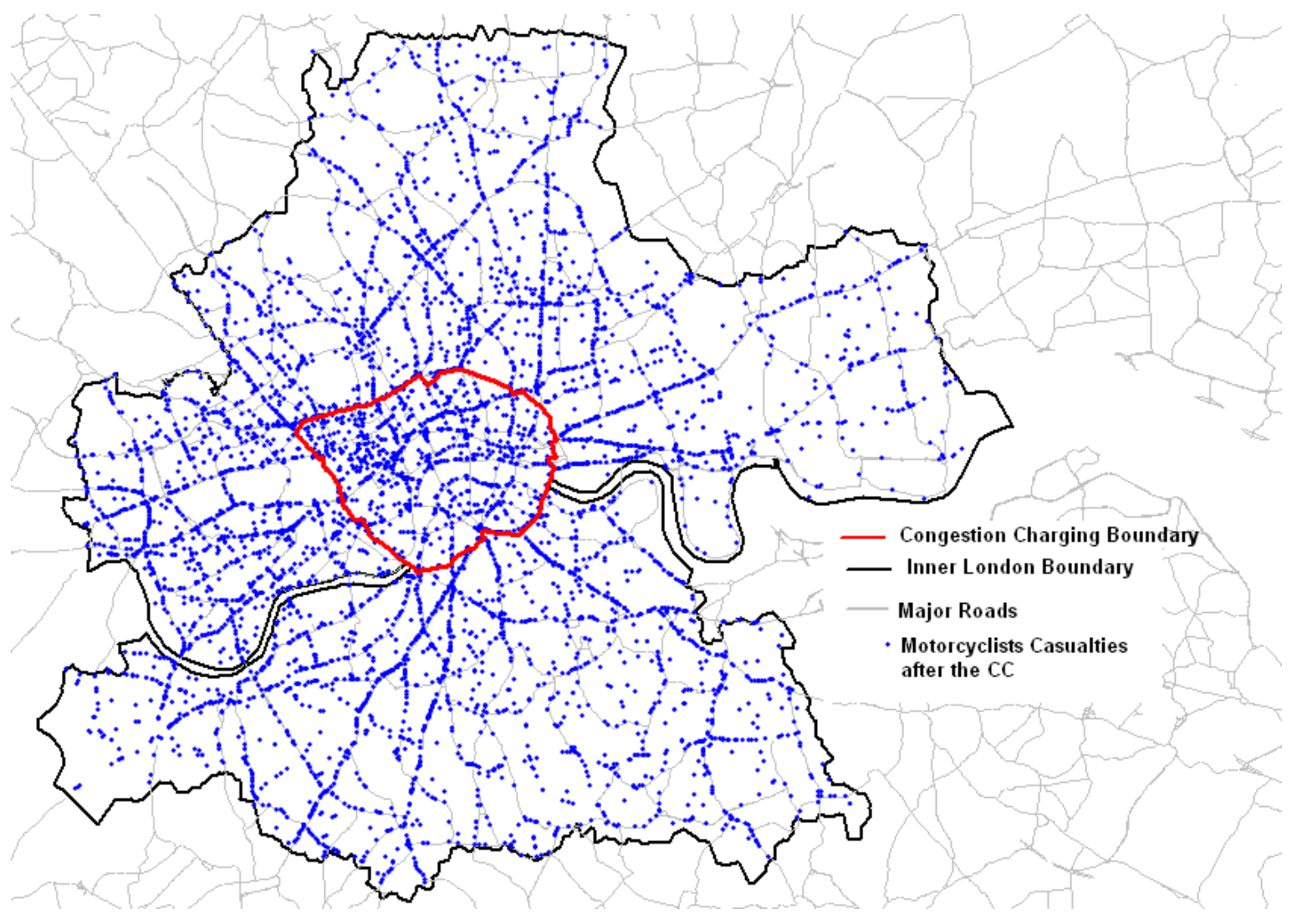

Figure 4

Motorcycle casualties within Inner London after implementation of the Congestion Charge 
Table 1a

Model for Congestion Charging Zone: during Charging Period (0700 - 1900 and Monday - Friday)

\begin{tabular}{|c|c|c|c|c|c|c|c|c|}
\hline & \multicolumn{2}{|c|}{ Motorcyclists } & \multicolumn{2}{|c|}{ Cyclists } & \multicolumn{2}{|c|}{ Car occupant } & \multicolumn{2}{|c|}{ Total } \\
\hline Noise Components & KSI & Slight & KSI & Slight & KSI & Slight & KSI & Slight \\
\hline Autoregressive, AR(1) & -0.093 & - & - & - & - & - & - & - \\
\hline Seasonal Autoregressive, SAR(1) & $-0.238 * *$ & - & - & - & - & - & - & - \\
\hline Moving Average, MA(1) & $0.995 * *$ & $0.862 * *$ & $0.987 * *$ & $0.929 * *$ & $0.994^{* *}$ & $0.893 * *$ & $0.930 * *$ & $0.884 * *$ \\
\hline Seasonal Moving Average, SMA(1) & $0.869 * *$ & $0.881 * *$ & $0.889 * *$ & $\mathbf{0 . 9 8 0}{ }^{\dagger}$ & 0.999 & $0.973 * *$ & $0.931 * *$ & $0.938 * *$ \\
\hline \multicolumn{9}{|l|}{ Control Parameter } \\
\hline $\ln ($ casualty crashes in London) & $6.24^{\dagger}$ & $24.297 *$ & $-1.783^{*}$ & 13.486 & 0.667 & $25.060 * *$ & $19.536 * *$ & $117.952 * *$ \\
\hline \multicolumn{9}{|l|}{ Intervention } \\
\hline \multicolumn{9}{|l|}{ Descriptive statistics } \\
\hline Series Length & 167 & 167 & 167 & 167 & 167 & 167 & 167 & 167 \\
\hline Number of Residuals & 154 & 154 & 154 & 154 & 154 & 154 & 154 & 154 \\
\hline Log-likelihood & -392 & -544 & -349 & -515 & -312 & -498 & -517 & -660 \\
\hline
\end{tabular}

${ }^{\dagger}$ 85\% confidence level, * 90\% confidence level, ** 95\% confidence level

\section{Table 1b}

Negative Binomial model for Congestion Charging Zone: during Charging Period (0700 - 1900 and Monday - Friday)

\begin{tabular}{|l|c|c|c|c|}
\hline & \multicolumn{2}{|c|}{ Cyclists } & \multicolumn{2}{c|}{ Car occupant } \\
\hline Explanatory variables & KSI & Slight & KSI & Slight \\
\hline Congestion charging (CC) & 0.127 & $\mathbf{0 . 1 4 4}$ & $\mathbf{- 0 . 8 1 0} * *$ & $\mathbf{- 0 . 3 8 9 * *}$ \\
\hline In(casualty crashes in London) & 0.877 & $\mathbf{1 . 8 8 5}^{* *}$ & 1.078 & $\mathbf{1 . 0 7 4}^{* *}$ \\
\hline Trend (linear) & 0.0012 & $\mathbf{0 . 0 0 1 4} * *$ & -0.0019 & $\mathbf{- 0 . 0 0 0 9 *}$ \\
\hline Constant & -5.877 & -11.950 & -7.847 & $-5.436^{* *}$ \\
\hline Overdispersion parameter (OP) & 0.0688 & $0.0369 * *$ & -1.511 & 0.0169 \\
\hline Descriptive statistics & & & & \\
\hline Observations & 167 & 167 & 167 & 167 \\
\hline Log likelihood & -354.06 & -569.87 & -286.73 & -514.76 \\
\hline
\end{tabular}

${ }^{\dagger} 85 \%$ confidence level, * 90\% confidence level, $* *$ 95\% confidence level 
Table 2a

Model for Congestion Charging Zone: during all time periods (0000 - 2400 and Monday - Sunday)

\begin{tabular}{|c|c|c|c|c|c|c|c|c|}
\hline & \multicolumn{2}{|c|}{ Motorcyclists } & \multicolumn{2}{|c|}{ Cyclists } & \multicolumn{2}{|c|}{ Car occupant } & \multicolumn{2}{|c|}{ Total } \\
\hline Noise Components & KSI & Slight & KSI & Slight & KSI & Slight & KSI & Slight \\
\hline Autoregressive, AR(1) & - & - & - & - & - & - & $0.289 * *$ & - \\
\hline Seasonal Autoregressive, SAR(1) & $-0.186^{* *}$ & - & - & - & - & - & - & - \\
\hline Moving Average, MA(1) & $0.995 * *$ & $0.868 * *$ & $0.920 * *$ & $0.899 * *$ & $0.975 * *$ & $0.931 * *$ & $0.981 * *$ & $0.868 * *$ \\
\hline Seasonal Moving Average, SMA(1) & $0.832 * *$ & $0.881^{* *}$ & $0.878 * *$ & $0.973 * *$ & $0.875 * *$ & $0.934^{* *}$ & $0.948^{* *}$ & $0.821^{* *}$ \\
\hline Control Parameter & & & & & & & & \\
\hline $\ln$ (casualty crashes in London) & 8.989** & $30.202 * *$ & -2.912 & 22.769* & -1.341 & 49.764** & $39.387 * *$ & 191.394** \\
\hline Intervention & & & & & & & & \\
\hline Congestion Charging (CC) & 0.105 & -3.245 & 0.815 & 1.378 & -1.733 & $-11.141 * *$ & -0.856 & -11.6811 \\
\hline Descriptive statistics & & & & & & & & \\
\hline Series Length & 167 & 167 & 167 & 167 & 167 & 167 & 167 & 167 \\
\hline Number of Residuals & 154 & 154 & 154 & 154 & 154 & 154 & 154 & 154 \\
\hline Log-likelihood & -425 & -566 & -366 & -539 & -423 & -585 & -562 & -697 \\
\hline
\end{tabular}

${ }^{\dagger} 85 \%$ confidence level, * 90\% confidence level, ** 95\% confidence level

Table 2b

Negative Binomial Model for Congestion Charging Zone: during all time periods (0000 - 2400 and Monday - Sunday)

Negative Binomial Model for Congestion Charging Zone: during all time periods (00
\begin{tabular}{|l|c|c|c|c|}
\hline & \multicolumn{2}{|c|}{ Cyclists } & \multicolumn{2}{c|}{ Car occupant } \\
\hline Explanatory variables & KSI & Slight & KSI & Slight \\
\hline Congestion charging (CC) & $\mathbf{0 . 2 8 8 *}$ & $\mathbf{0 . 1 7 3} * *$ & $\mathbf{- 0 . 2 9 4}$ & $\mathbf{- 0 . 3 1 8 * *}^{* *}$ \\
\hline ln(casualty crashes in London) & $\mathbf{1 . 3 5 3}^{* *}$ & $\mathbf{1 . 8 5 5}^{* *}$ & 0.279 & $\mathbf{0 . 7 2 0} * *$ \\
\hline Trend (linear) & 0.002 & $\mathbf{0 . 0 0 1 9} *$ & $\mathbf{- 0 . 0 0 2 * *}$ & 0.0001 \\
\hline Constant & -9.434 & $-11.471^{* *}$ & -0.218 & -1.719 \\
\hline Overdispersion parameter (OP) & 0.0349 & 0.0321 & 0.128 & 0.010 \\
\hline Descriptive statistics & & & & \\
\hline Observations & 167 & 167 & 167 & 167 \\
\hline Log likelihood & -376.59 & -599.65 & -423.54 & -609.74 \\
\hline
\end{tabular}

${ }^{\dagger} 85 \%$ confidence level, * 90\% confidence level, ** 95\% confidence level 
Table 3

Model for Inner London (excluding the Congestion Charging Zone): during the Charging Period (0700 - 1900 and Monday - Friday)

\begin{tabular}{|c|c|c|c|c|c|c|c|c|}
\hline & \multicolumn{2}{|c|}{ Motorcyclists } & \multicolumn{2}{|c|}{ Cyclists } & \multicolumn{2}{|c|}{ Car occupant } & \multicolumn{2}{|c|}{ Total } \\
\hline Noise Components & KSI & Slight & KSI & Slight & KSI & Slight & KSI & Slight \\
\hline Autoregressive, AR(1) & - & $-0.161^{*}$ & - & - & - & - & - & - \\
\hline Seasonal Autoregressive, SAR(1) & - & - & - & - & - & - & $0.223^{* *}$ & - \\
\hline Moving Average, MA(1) & $0.877 * *$ & $0.824 * *$ & $0.890 * *$ & $0.899 * *$ & $0.842 * *$ & $0.884 * *)$ & $0.815 * *$ & $0.941 * *)$ \\
\hline Seasonal Moving Average, SMA(1) & 0.999 & $0.863 * *$ & $0.973 * *$ & $0.973 * *$ & $0.977^{*}$ & $0.957 * *$ & 0.988 & $0.867 * *$ \\
\hline \multicolumn{9}{|l|}{ Control Parameter } \\
\hline $\ln$ (casualty crashes in London) & $30.019 * *$ & 153.773** & $8.987 * *$ & $22.770 * *$ & $21.601 * *$ & $265.107 * *$ & 90.332** & 735.545** \\
\hline \multicolumn{9}{|l|}{ Intervention } \\
\hline Congestion Charging (CC) & 4.275 & $16.271 * *$ & 1.063 & 1.377 & -0.696 & -8.192 & 5.126 & 18.601 \\
\hline \multicolumn{9}{|l|}{ Descriptive statistics } \\
\hline Series Length & 167 & 167 & 167 & 167 & 167 & 167 & 167 & 167 \\
\hline Number of Residuals & 154 & 154 & 154 & 154 & 154 & 154 & 154 & 154 \\
\hline Log-likelihood & -490 & -635 & -440 & -539 & -589 & -716 & -700 & -816 \\
\hline
\end{tabular}

85\% confidence level, * 90\% confidence level, ** 95\% confidence level 
Table 4

Model for Inner London (excluding the Congestion Charging Zone): during all time periods (0000 - 2400 and Monday - Sunday)

\begin{tabular}{|c|c|c|c|c|c|c|c|c|}
\hline & \multicolumn{2}{|c|}{ Motorcyclists } & \multicolumn{2}{|c|}{ Cyclists } & \multicolumn{2}{|c|}{ Car occupant } & \multicolumn{2}{|c|}{ Total } \\
\hline Noise Components & KSI & Slight & KSI & Slight & KSI & Slight & KSI & Slight \\
\hline Autoregressive, AR(1) & - & $-0.397 * *$ & - & - & - & - & & - \\
\hline Seasonal Autoregressive, SAR(1) & & - & - & - & - & - & - & - \\
\hline Moving Average, MA(1) & $0.85 * *$ & $0.639 * *$ & $0.896 * *$ & $0.850 * *$ & $0.825 * *$ & $0.891 * *$ & $0.719 * *$ & $0.805 * *$ \\
\hline Seasonal Moving Average, SMA(1) & $0.893 * *$ & $0.926 * *$ & $0.879 * *$ & $0.840 * *$ & 0.993 & $0.960 * *$ & $0.765 * *$ & $0.894 * *$ \\
\hline \multicolumn{9}{|l|}{ Control Parameter } \\
\hline $\ln$ (casualty crashes in London) & $39.065 * *$ & 211.171** & 12.440 & $91.475 * *$ & 40.197** & $540.463^{* *}$ & $164.041 * *$ & 1191.374** \\
\hline \multicolumn{9}{|l|}{ Intervention } \\
\hline Congestion Charging (CC) & 4.223 & $40.059 * *$ & -0.013 & 8.443 & -1.371 & -22.218 & 5.604 & 10.581 \\
\hline \multicolumn{9}{|l|}{ Descriptive statistics } \\
\hline Series Length & 167 & 167 & 167 & 167 & 167 & 167 & 167 & 167 \\
\hline Number of Residuals & 154 & 154 & 154 & 154 & 154 & 154 & 154 & 154 \\
\hline Log-likelihood & -535 & -656 & -486 & -657 & -589 & -801 & -700 & -806 \\
\hline
\end{tabular}

${ }^{\dagger} 85 \%$ confidence level, * 90\% confidence level, ** 95\% confidence level 
Table 5

Model for Outer London: during the Charging Period (0700 - 1900 and Monday - Friday)

\begin{tabular}{|c|c|c|c|c|c|c|c|c|}
\hline & \multicolumn{2}{|c|}{ Motorcyclists } & \multicolumn{2}{|c|}{ Cyclists } & \multicolumn{2}{|c|}{ Car occupant } & \multicolumn{2}{|c|}{ Total } \\
\hline Noise Components & KSI & Slight & KSI & Slight & KSI & Slight & KSI & Slight \\
\hline Autoregressive, AR(1) & 0.142 & - & - & - & - & - & - & - \\
\hline Seasonal Autoregressive, SAR(1) & - & - & - & - & - & - & - & - \\
\hline Moving Average, MA(1) & $0.867 * *$ & $0.513^{* *}$ & $0.879 * *$ & $0.867 * *$ & $0.731 * *$ & $0.824 * *$ & $0.778 * *$ & $0.842 * *$ \\
\hline Seasonal Moving Average, SMA(1) & & $0.964 * *$ & $0.954^{* *}$ & $0.716 * *$ & $0.879 * *$ & $0.935 * *$ & $0.858 * *$ & $0.959 * *$ \\
\hline Control Parameter & & & & & & & & \\
\hline $\ln$ (casualty crashes in London) & 45.070** & 177.156** & 3.707 & $42.920 * *$ & 81.779** & 611.513** & $147.646 * *$ & 1022.37** \\
\hline Intervention & & & & & & & & \\
\hline Congestion Charging (CC) & 6.755 & $34.742 *$ & $3.018 *$ & 8.103 & 0.871 & 11.008 & 12.153 & 21.44 \\
\hline Descriptive statistics & & & & & & & & \\
\hline Series Length & 167 & 167 & 167 & 167 & 167 & 167 & 167 & 167 \\
\hline Number of Residuals & 166 & 154 & 154 & 154 & 154 & 154 & 154 & 154 \\
\hline Log-likelihood & -575 & -703 & -417 & -600 & -609 & -818 & -682 & -862 \\
\hline
\end{tabular}

Log-likelihood

$85 \%$ confidence level, * 90\% confidence level, ** 95\% confidence level 
Table 6

Model for Outer London: during all time periods (0000 - 2400 and Monday - Sunday)

\begin{tabular}{|c|c|c|c|c|c|c|c|c|}
\hline \multirow[b]{2}{*}{ Noise Components } & \multicolumn{2}{|c|}{ Motorcyclists } & \multicolumn{2}{|c|}{ Cyclists } & \multicolumn{2}{|c|}{ Car occupant } & \multicolumn{2}{|c|}{ Total } \\
\hline & KSI & Slight & KSI & Slight & KSI & Slight & KSI & Slight \\
\hline Autoregressive, AR(1) & - & - & 0.122 & - & - & - & - & - \\
\hline Seasonal Autoregressive, SAR(1) & $-0.175^{*}$ & - & -0.169 & - & - & - & - & - \\
\hline Moving Average, MA(1) & $0.906 * *$ & $0.873 * *$ & $0.774 * *$ & $0.666 * *$ & $0.660 * *$ & $0.586 * *$ & $0.624 * *$ & $0.784 * *$ \\
\hline Seasonal Moving Average, SMA(1) & $0.784^{* *}$ & $0.898 * *$ & $0.714^{* *}$ & $0.697 * *$ & $0.850 * *$ & $0.449 * *$ & $0.851 * *$ & $0.911 * *$ \\
\hline \multicolumn{9}{|l|}{ Control Parameter } \\
\hline In(casualty crashes in London) & -0.249 & 43.835** & -1.841 & 26.617 & $112.610 * *$ & $875.069 * *$ & $224.710 * *$ & 1553.21** \\
\hline \multicolumn{9}{|l|}{ Intervention } \\
\hline Congestion Charging (CC) & 1.291 & 2.029 & 3.017 & -6.039 & 11.706 & 27.595 & 16.788 & $-59.158 *$ \\
\hline \multicolumn{9}{|l|}{ Descriptive statistics } \\
\hline Series Length & 167 & 167 & 167 & 167 & 167 & 167 & 167 & 167 \\
\hline Number of Residuals & 154 & 154 & 154 & 154 & 154 & 154 & 154 & 154 \\
\hline Log-likelihood & -383 & -592 & -477 & -665 & -696 & -966 & -756 & -843 \\
\hline
\end{tabular}

Log-likelihood

$85 \%$ confidence level, * 90\% confidence level, ** 95\% confidence level 
Table 7

Models for motorcyclist casualties with alternative control variable

\begin{tabular}{|c|c|c|c|c|c|c|c|c|c|c|c|c|}
\hline \multirow[b]{3}{*}{ Noise Components } & \multicolumn{4}{|c|}{ Congestion Charging Zone } & \multicolumn{4}{|c|}{ Inner London excluding the CC zone } & \multicolumn{4}{|c|}{$\begin{array}{c}\text { Outer London } \\
\end{array}$} \\
\hline & \multicolumn{2}{|c|}{ 0700-1900 } & \multicolumn{2}{|c|}{$0000-2400$} & \multicolumn{2}{|c|}{ 0700-1900 } & \multicolumn{2}{|c|}{$0000-2400$} & \multicolumn{2}{|c|}{ 0700-1900 } & \multicolumn{2}{|c|}{$0000-2400$} \\
\hline & KSI & Slight & KSI & Slight & KSI & Slight & KSI & Slight & KSI & Slight & KSI & Slight \\
\hline Autoregressive, AR(1) & -0.106 & - & - & - & - & 0.014 & - & $-0.183^{*}$ & $0.781^{* *}$ & - & - & - \\
\hline $\begin{array}{l}\text { Seasonal Autoregressive, } \\
\text { SAR(1) }\end{array}$ & $-0.245^{* *}$ & - & $-0.168 *$ & - & - & - & - & - & - & - & -0.135 & - \\
\hline Moving Average, MA(1) & $0.935 * *$ & $0.867 * *$ & $0.994 * *$ & $0.876 * *$ & $0.901 * *$ & $0.949 * *$ & $0.861 * *$ & $11.912^{* *}$ & $0.602 * *$ & $0.963 * *$ & $0.720 * *$ & $0.574 * *$ \\
\hline $\begin{array}{l}\text { Seasonal Moving Average, } \\
\text { SMA(1) }\end{array}$ & $0.894 * *$ & $0.902 * *$ & $0.863 * *$ & $0.905^{* *}$ & 0.992 & $0.777 * *$ & $0.897 * *$ & $9.958 * *$ & - & $0.909 * *$ & $0.914 * *$ & $0.934 * *$ \\
\hline \multicolumn{13}{|l|}{ Control Parameter } \\
\hline $\begin{array}{l}\text { ln(motorcycle casualty } \\
\text { crashes in London) }\end{array}$ & $7.907 * *$ & $33.374^{* *}$ & $9.147^{*}$ & $42.157 * *$ & $33.079 * *$ & $119.17 * *$ & $48.315^{* *}$ & $163.77 * *$ & $3.347 * *$ & $94.342 * *$ & $23.288 * *$ & $146.64 * *$ \\
\hline \multicolumn{13}{|l|}{ Intervention } \\
\hline Congestion Charging (CC) & 0.0962 & -3.817 & 0.021 & $-6.939 *$ & 1.733 & -2.008 & -0.059 & 19.35** & 1.944 & 3.167 & 2.626 & -13.77 \\
\hline \multicolumn{13}{|l|}{ Descriptive statistics } \\
\hline Series Length & 167 & 167 & 167 & 167 & 167 & 167 & 167 & 167 & 167 & 167 & 167 & 167 \\
\hline Number of Residuals & 154 & 154 & 154 & 154 & 154 & 154 & 154 & 154 & 166 & 154 & 154 & 154 \\
\hline Log-likelihood & -388 & -535 & -421 & -555 & -471 & -620 & -512 & -633 & -529 & -618 & -548 & -657 \\
\hline
\end{tabular}

${ }^{\dagger} 85 \%$ confidence level, * 90\% confidence level, ** 95\% confidence level 